\title{
Learning proverbs through telecollaboration with Japanese native speakers: facilitating L2 learners' intercultural communicative competence
}

\author{
Maki Hirotani $1^{\text {* }^{*}}$ and Kiyomi Fujii ${ }^{2}$
}

* Correspondence:

hirotani@rose-hulman.edu

${ }^{1}$ Rose-Hulman Institute of

Technology, 5500 Wabash Ave.,

Terre Haute, IN 47803, USA

Full list of author information is

available at the end of the article

\begin{abstract}
Telecollaboration has been considered to have great potential for the development of L2 learners' intercultural communicative competence (ICC), so an examination of what benefits L2 learners receive through telecollaboration is necessary. Also, L2 learners' use of culturally specific expressions, such as proverbs, has not been adequately investigated. The present study investigated the effects of telecollaboration on L2 learners' perceptions of their ICC knowledge and skills in relation to one type of verbal communication (proverbs) in Japanese. Nineteen L2 novice learners of Japanese were involved in the study, and they telecollaborated with 23 native speakers of Japanese using Facebook. They learned Japanese proverbs through Facebook videos introduced by their Japanese peers, followed by in-class follow up sessions and a reflection log activity, and they then performed skits in Japanese. Their perceptions of their ICC knowledge and skills were compared using the pre- and the post-questionnaires, and their language production was analyzed. The study found that students gained a sense of accomplishment in learning the target element of verbal communication; however, they did not always execute the expressions in appropriate situations.
\end{abstract}

Keywords: Telecollaboration, Intercultural communicative competence, Japanese as a foreign language, Proverbs

\section{Introduction}

With the rise of globalization, we need the ability to communicate with people from other societies in various settings, including business, school, online, and in daily life settings (Garrett-Rucks, 2016). The Modern Language Association (MLA) Ad Hoc Committee on Foreign Languages (MLA, 2007) reported the need for students acquiring translingual and transcultural competence to "operate between languages" (p. 237) in the context of today's globalized society. L2 (Second language) learners are required to develop their intercultural communicative competence (ICC), which Byram (1997) defines as the ability to communicate appropriately and effectively with people from linguistically and culturally diverse backgrounds. The current situation in the US is that the majority of L2 learners rarely continue their language studies to advanced levels (Garrett-Rucks, 2016). Thus, foreign language teachers now need to incorporate

(c) The Author(s). 2019 Open Access This article is distributed under the terms of the Creative Commons Attribution 4.0 International License (http://creativecommons.org/licenses/by/4.0/), which permits unrestricted use, distribution, and reproduction in any medium, provided you give appropriate credit to the original author(s) and the source, provide a link to the Creative Commons license, and indicate if changes were made. 
culturally meaningful content in their beginner's level curriculum (Garrett-Rucks, 2016) in order to facilitate the development of L2 learners' ICC.

Given the importance of the development of learners' ICC, many theoretical frameworks, such as Bennett's Developmental Model of Intercultural Sensitivity (Bennett, 1993) and Byram's multimodal model of intercultural competence (Byram, 1997), have been proposed. In addition to cultural knowledge of the target culture, ICC requires the knowledge of language communication, including verbal and non-verbal communication and the ability to use appropriate expressions in the target language.

Telecollaboration has emerged in foreign language education as a potential tool to deal with these issues. Telecollaboration is the use of online communication tools, in which language learners who are located in geographically distant areas gather online and collaborate on projects under guided instruction (Lewis \& O'Dowd, 2016). A number of telecollaboration projects have been conducted (e.g., Belz, 2002; Belz \& Kinginger, 2003; Cunningham, 2016; Gonzáles, 2013), and the results indicate that telecollaboration has great potential to develop L2 learners' ICC and pragmatic competence (Lewis \& O'Dowd, 2016). Nonetheless, while telecollaboration projects and publications involving Indo-European languages as the L2 have increased in recent years, the number of journal and book publications investigating research of Asian languages as the L2 is "disappointingly small" (Lewis \& O’Dowd, 2016, p. 25). We need to know what benefits L2 learners would actually receive through telecollaboration. For instance, we can investigate if L2 learners improve their perceptions of their ICC knowledge and skills in a target L2, such as Japanese. Moreover, we need to find out what specific telecollaborative activities and instruction are effective for the learning of target expressions in the target language. To investigate these issues, more studies are necessary.

The current investigation is an attempt to answer some of these questions regarding telecollaboration and language learning, specifically in the context of Japanese. It is a four-week exploratory study in which L2 novice learners of Japanese telecollaborated with native speakers of Japanese using Facebook to learn Japanese proverbs. The project dealt with both verbal (proverbs) and non-verbal (gestures) communication; however, the present study focused solely on verbal expressions (proverbs) to closely look at the learners' learning experience. Proverbs reflect the cultural values and beliefs of one's society (Fischer \& Yoshida, 1968; Mieder, 2004). Understanding the values and beliefs of one's own culture and those of the target culture is essential to developing one's own ICC, but we know little about how L2 learners use proverbs. This study examines the effects of telecollaboration on L2 learners' perceptions of their ICC knowledge and skills in relation to the targeted elements of language communication (i.e., proverbs) and on their use of these elements in their language production. Examining learners' understanding of proverbs should shed light on the potential benefits of using telecollaboration for the development of L2 learners' ICC.

\section{Literature review}

\section{Intercultural communicative competence}

Intercultural communicative competence (ICC) is the ability to communicate appropriately and effectively with people from linguistically and culturally diverse backgrounds (Byram, 1997; Deardorff, 2006; Garrett-Rucks, 2016). While there are many ICC models 
available (e.g., Bennett, 1993; Byram, 1997; Deardorff, 2006), this section details Bennett's (1993) Developmental Model of Intercultural Sensitivity (DMIS), which was used for this study. The reason for selecting this model was twofold. First, Bennett's DMIS is one of the most commonly used frameworks in foreign language education (Garrett-Rucks, 2016). Second, the ICC rubric (AACU rubric; see the Methods for details) that we referred to for the present study was based on this model.

Bennett (1993) provided a linear model of intercultural sensitivity that focuses on developing sensitivity to cultural differences. The model comprises two main stages: ethnocentric and ethnorelative. At the ethnocentric stage, learners' culture is central to their worldview when they compare it to other cultures. The ethnocentric stage is further divided into three sub-stages: I. denial, II. defense, and III. minimization. The second major stage is the ethnorelative stage. At this stage, learners' culture is no longer considered to be central when comparing it to other cultures, and "cultural difference is neither good nor bad" (Bennett, 1993, p. 46) but just different. This stage is also further divided into three sub stages: IV. acceptance, V. adaptation, and VI. integration.

According to Bennett (1993), while learners can recognize superficial differences in language behavior in earlier stages of intercultural sensitivity (i.e., ethnocentric stages), they can recognize and accept "profound cultural differences" (p. 48) at the ethnorelative stages, "the deeper level of cultural relativity" (p. 48). Successful intercultural speakers need to have the linguistic and cultural knowledge of the target society and the ability to use contextually appropriate expressions and behaviors in the target language (Belz, 2003; Bennett, 1993; Byram, 1997; Taguchi, 2015b), that is, L2 pragmatic competence. Pragmatic competence for language communication is an essential component of ICC. Bennett (1993) claimed that students need to have the ability to understand the cultural values and beliefs of the target culture and use culturally appropriate language expressions in social contexts to move on to the ethnorelative stage. As such, proverbs exemplify language expressions that present a rich source of potential pragmatic instructional material.

\section{Proverbs}

A proverb is a concise traditional expression "which contains wisdom, truth, morals, and traditional views in a metaphorical, fixed and memorizable form and which is handed down from generation to generation" (Mieder, 2004, p. 3). Proverbs reflect the values and beliefs of a society (Mieder, 2004). As researchers (Fischer \& Yoshida, 1968) pointed out, by studying the proverbs of a given society, we can begin to understand its cultural values and beliefs. As such when looking at Japanese proverbs, we see what is valued in Japanese society. For example, the following proverbs emphasize the value of silence over words (Dabaghi, Pishbin, \& Niknasab, 2010): "chinmoku wa kin, yuuben wa gin [silence is gold, eloquence is silver]" and "iwanu ga hana [better leave it unsaid]." As another example of Japanese values, hard work is expected and encouraged to succeed in society, and we see proverbs that reflect this value, such as "gakumon ni chikamichi nashi [there are no shortcuts to learning]". In addition to cultural values and beliefs, Japanese proverbs often reflect morals and lessons (Dabaghi et al., 2010), such as respecting old people and teachers. For instance, the following proverb emphasizes the importance of respecting one's teacher: "sanshaku sagatte shi no kage o fumazu [a student must never forget to honor their 
teacher (literally means: you must walk three feet behind your teacher and must never step on your teacher's shadow)]." Finally, another major characteristic of Japanese proverbs is that many proverbs originally borrowed from China, such as "ichi o kiite juu o shiru [A word is enough to a wise man]" from the Analects of Confucius and have become embedded into the Japanese language.

Nonetheless, as researchers (Ellis, 2012; Weinert, 1995) claimed, there have been few language learning studies on formulaic language, including idioms (Irujo, 1986) and proverbs. Irujo's (1986) study revealed that L2 learners used their L1 (first language) knowledge when comprehending and producing L2 idioms: L2 learners performed better for L2 comprehension and production if the idioms are identical or similar to their L1 equivalents in form and meaning (e.g., English: to be in charge vs. Spanish: estar a cargo [to be at charge]), whereas they performed poorly if the idioms are different from their L1 expressions (e.g., to pull his leg vs. tomarle el pelo [to take to him by the hair]) (Irujo, 1986).

Pedagogically speaking, it is worth investigating the use of proverbs by second and foreign language learners because textbooks generally do not include an extensive section of proverb-related explanations and activities. While many proverbs are relatively easy grammatical structures that learners already know (e.g., $X$ wa $Y$ desu [Regarding $\mathrm{X}$, (it is) Y]), some proverbs are not pragmatically easy to understand (Neale, 2015). When Neale (2015) examined two pairs of English and Japanese proverbs that are considered equivalent in meaning (Look before you leap vs. nen-niwa-nen-o-ireyo; The proof of the pudding is in the eating vs. ron-yori-shoko) to see if there were any differences, he found many subtle pragmatic differences between the pairs of proverbs that he analyzed. Even though the proverbs were considered "equivalent," these subtle pragmatic differences may affect learners' acquisition of the expressions, especially if the learners are studying the L2 in a setting that doesn't allow them to regularly interact with native speakers of the target language or their culture. Fortunately, using modern communication tools provides the opportunity to reach beyond traditional methods of instruction and bridge the gap between learners and the culture of their target language.

\section{Telecollaboration}

Research shows the importance of teaching pragmatics through explicit instruction in the classroom (Cunningham, 2016; Taguchi, 2015a, b; Taguchi \& Sykes, 2013). Yet the textbooks that language learners use rarely deal with these topics (Bardovi-Harlig, 2001; Cohen, 2011; Jeon \& Kaya, 2006). Bardovi-Harlig (2001) claimed that textbooks tend to introduce grammar without pragmatic information. Providing authentic materials as a model for practicing pragmatic expressions is difficult due to the content depending on the contextual setting (Taguchi, 2015a). One possible solution is the implementation of telecollaboration in the language curriculum that would allow learners to explore the use of pragmatic expressions through the creation of skits that define the context.

Telecollaboration is the use of online communication tools by language learners who are located in geographically distant areas who gather online and collaboratively work on projects under guided instruction to develop their foreign language skills and ICC (Lewis \& O'Dowd, 2016). There have been an increasing number of studies on the development of pragmatic competence through telecollaboration (e.g., Belz \& Vyatkina, 2005; Cunningham, 2016; Gonzáles, 2013; Kakegawa, 2009; Takamiya \& Ishihara, 2013), and these studies 
indicate that teachers' interventions and explicit instruction are crucial for the success of collaboration. Previous studies revealed various benefits for learning pragmatics through telecollaboration: facilitating learners' awareness of the use of target expressions (Kakegawa, 2009), learning how to modify the directness of requests (Cunningham, 2016), and increasing the production of refusal statements (Takamiya \& Ishihara, 2013).

Kakegawa (2009) investigated 11 pre-intermediate learners of Japanese use of sentence final particles (SFPs) through a 12-week telecollaboration project. The participants exchanged emails with 17 native speakers of Japanese, and usage of the target SFPs was reinforced through in-class explicit instruction interventions. The results showed that the participants used SFPs more frequently and also used more types of SPFs after the interventions. Regarding the quality of the use of SFPs (i.e., contextual appropriateness), while the participants did not always use SFPs appropriately (e.g., the accuracy rate of "ne", one type of SFPs: 73.6\%; that of "yone": $33.3 \%$ at the time of the last data collection), the contextual appropriateness improved through the interventions (e.g., from $56.9 \%$ at the first data collection to $73.6 \%$ at the last data collection for the use of "ne"). The author concluded that telecollaboration with direct intervention has a positive impact on learner awareness of the use of SFPs.

As another example, Takamiya and Ishihara (2013) conducted a case study of an advanced JFL (Japanese as a foreign language) learner's development of pragmatic competence in the use of refusals. They analyzed blog entries of learners of Japanese in an exchange with EFL (English as a foreign language) learners during a 15-week course. Through discussions of these blogs with native speakers and peers about the use of refusals in Japanese, the learner's pragmatics competence improved, as did the accurate production of refusal statements. This study demonstrates that learners' pragmatic competence can be developed through explicit discussions with native speakers and peers.

The advent of social networking makes the use of telecollaboration even more attractive as a language learning tool, and there have been an increasing number of telecollaboration projects using social networking services (SNS), including Facebook (Gonzáles, 2013; Lewis \& O'Dowd, 2016; McBride, 2009; Mitchell, 2012). In addition to the benefits of tellecollaboration listed above (i.e., providing students with pedagogically useful foreign language experiences and facilitating the improvement of L2 learners' linguistic competency), previous studies have reported an increase in learners' motivation toward the target language (Lomicka \& Lord, 2016; Mitchell, 2012), positive reactions toward the use of SNS for collaborative activities with native speakers of the target language (Stevenson \& Liu, 2010), and the improvement of L2 learners' cultural competency (Mitchell, 2012).

\section{Research questions}

The present study examined the effects of telecollaboration with Japanese native speakers on the perceptions of L2 novice learners of Japanese with regard to their verbal communication knowledge and skills, and on the use of these expressions in their language production. We formulated the following research questions:

RQ1. Did L2 learners of Japanese improve their perceptions of their own intercultural communicative competence for verbal communication knowledge and skills after participating in this project? 
RQ2: Did they use proverbs with grammatical accuracy, correct pronunciation, and in the appropriate context?

\section{Methods}

\section{Overview of the proverbs project}

The current investigation is an exploratory study as part of a four-month interclass telecollaboration in which university learners of Japanese in the US and learners of English in Japan participated in a series of asynchronous L1 and L2 video exchanges on Facebook. The targeted project for the present study lasted for 4 weeks with consideration of curriculum difference between the two institutions. ${ }^{1}$ In addition to verbal communication, non-verbal communication skills are required to achieve the ethnorelative stages of DMIS, and the project also dealt with gestures as one type of non-verbal communication (i.e., the learners also learned gestures through the project). However, as stated previously, the present study focused solely on verbal communication (proverbs) to closely look at the learning outcomes through the project. The researchers in the present study were the instructors, one for the Japanese class in the US and one for the English class in Japan.

The students first introduced L1 proverbs in their L1 to students at their partner school through Facebook videos. After several in-class sessions reviewing proverbs that were introduced in the videos, they worked on a reflection log and then performed skits in their L2, using the expressions they had learned through these activities. A set of self-evaluation questionnaires about their L2 verbal communication knowledge and skills were conducted before and after the project. The project procedures are summarized in Fig. 1.

\section{Participants}

Nineteen novice-level learners of Japanese (16 males and 3 females) enrolled in the first 10-week quarter of second-year Japanese at a university in the Midwestern US were involved in this study. The participants used Genki II (Banno, Ohno, Sakane, Shinagawa, \& Takashiki, 2011), a novice-level textbook, and had completed 120 contact hours during their first year of Japanese. The participants included seven native speakers of English, ten of Chinese, one of Korean, and one of Arabic. The class met four times a

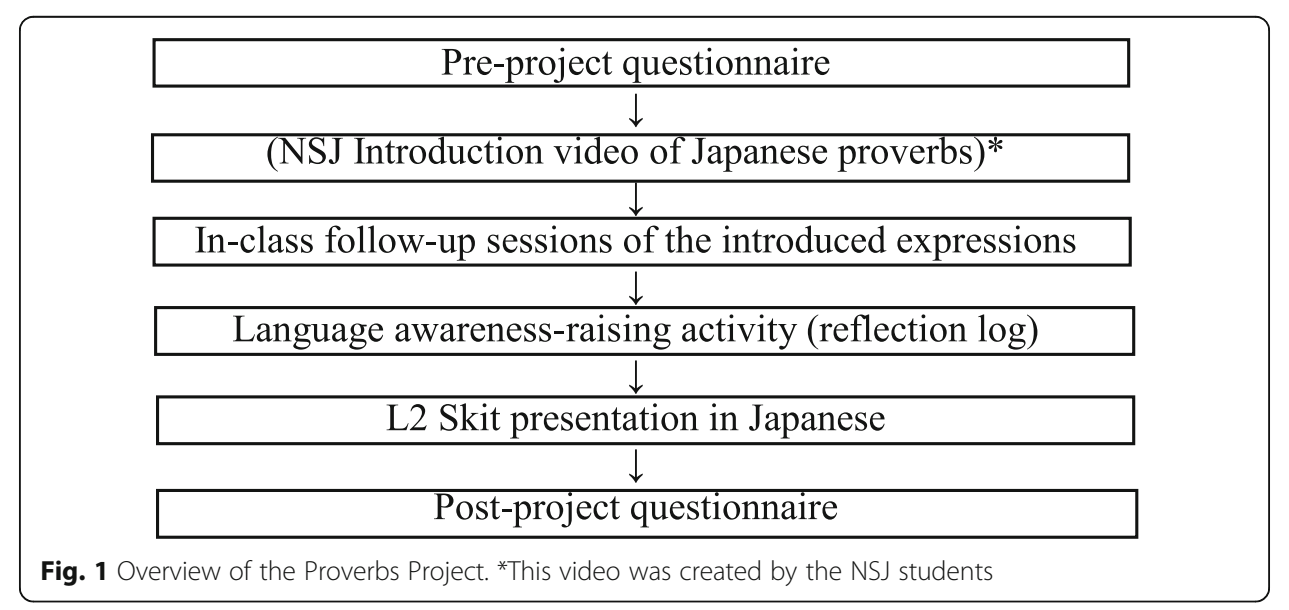


week (50 min./class) and required regular homework, including grammar-related listening, writing, and reading assignments. The participants telecollaborated with 23 L1 Japanese undergraduates in a general English course in Japan (NSJ students). The class at each institution was divided into small groups consisting of four or five students. All members in each group collaboratively produced their L1 proverbs introduction video as well as their L2 skits. The present study focuses on data collected from the learners of Japanese.

\section{Materials}

Facebook

We used Facebook as a communication tool. Facebook has been recognized as the most popular SNS among college students in the U.S. (http://iop.harvard.edu/use-so cial-networking-technology), and we reviewed the benefits of its use for telecollaboration earlier. Two private Facebook pages, a Japanese page and an English page, were created. When communicating in Japanese, students used the Japanese page, and when communicating in English, they used the English page. Thus, NSJ students posted Japanese proverbs introduction videos on the Japanese page. ${ }^{2}$ The participants viewed the NSJ videos and communicated with the NSJ students on that same page (see Fig. 2).

\section{L1 proverbs videos}

Each NSJ group produced one Japanese proverbs introduction video (NSJ video). The reason that proverbs were introduced by NSJ students, instead of the Japanese instructor, is twofold. First, a pilot study conducted before this project revealed that the learners of Japanese enjoyed learning expressions from native Japanese-speaking peers and that the activity positively affected their motivation to learn the target expressions. Also, learners can reflect on the expressions used in their own society when producing the L1 introduction videos because ICC requires knowledge of not only the target culture, but also one's own culture (Byram, 1997).

Each NSJ group was required to select at least four proverbs and introduce them through their NSJ video. The pilot study also revealed that native Japanese speakers tended to introduce expressions to their counterparts that were too easy. Thus, prior to the assignment, several examples of level-appropriate expressions were provided to the NSJ students. NSJ students first introduced each expression on the whiteboard, briefly explained its usage in Japanese, and performed a short Japanese skit for each expression in their video.

The following is an example of how the NSJ students introduced each expression. Two NSJ students (A and B) showed "gojuppo-hyappo [Six of one and half a dozen of the other]" on the whiteboard.

A: ee, gojuppo-hyappo. sukoshi no chigai wa, arukotowa aruga, honshitsuteki niwa onaji dato iu imi desu. [Um ... Gojuppo-hyappo. This means there is a slight difference between the two, but essentially, they are the same.]

(Skit starts)

B: oo, sakki no tesuto wa nanten datta? [Hey, what did you get on the latest exam?]

A: a-, 20-ten dattan dakedo. mata yatteshimatta. [Um, I got a 20. I did it again...] 

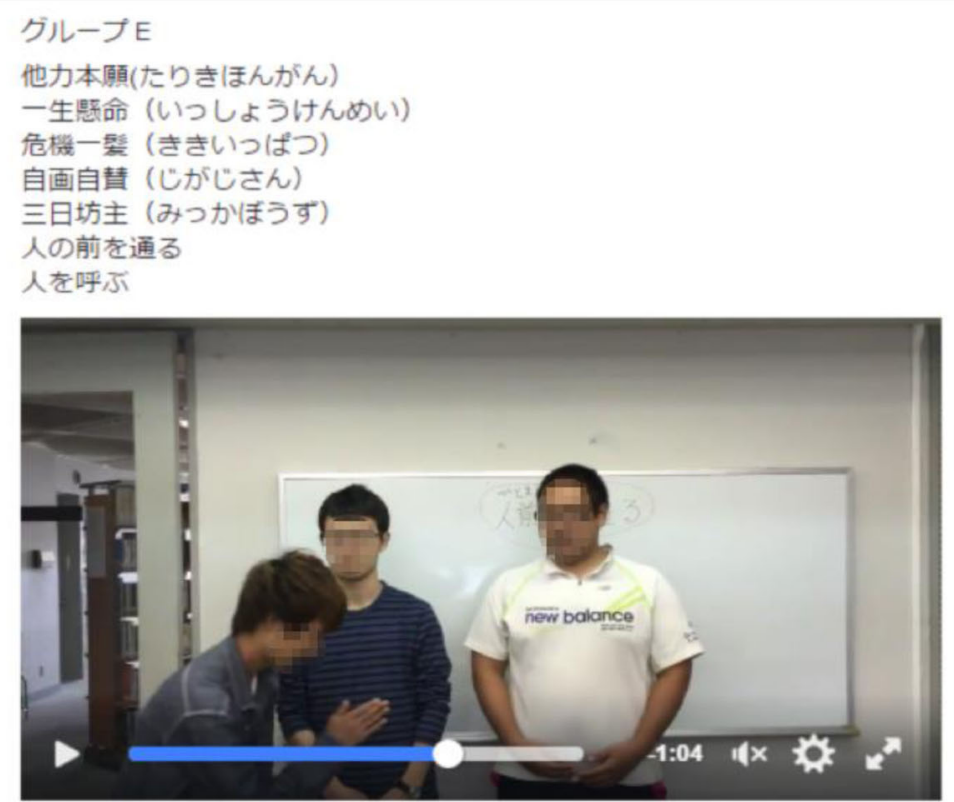

にはなさんはすごいですね.ビデオはとてもよかったと思いま した。ちょつと質閆があります.「じがじさん」はよくない言褁ですがビテ オで友だちと使うはいいですがちょつと意地悪なことばてすか。人の前を通る のジェスチャーの意味はちょつとわかりません。「こんにちは」とジェスチャ 一の音味は同じですか。「しつれいします」とジエスチャーの童味は同じです か.ありがとうございます。( - - )

Fig. 2 Screenshot of the NSJ Video

B: ore wa 30-ten. yappari ore no houga, ten ga ue nanda. atama no deki ga iikara. [I got a 30. Hey, my score was higher than yours. I'm smarter than you.]

A: docchi ni shitatte, 20-ten mo 30-ten mo warui darou. gojuppo-hyappo dayo. [In any case, both 20 and 30 are bad. Gojuppo-hyappo isn't it?]

Each NSJ group posted their L1 video on Facebook. A total of 20 Japanese proverbs were introduced by five NSJ groups (see Table 3).

\section{Expression list}

The pilot study also revealed that novice learners of Japanese preferred to have a list of expressions used in NSJ videos as a supplement (see Fig. 3). Native speakers' speech is not often easy enough for novice learners to understand for several reasons. First, native speakers often use expressions unfamiliar to learners. Second, learners have not 


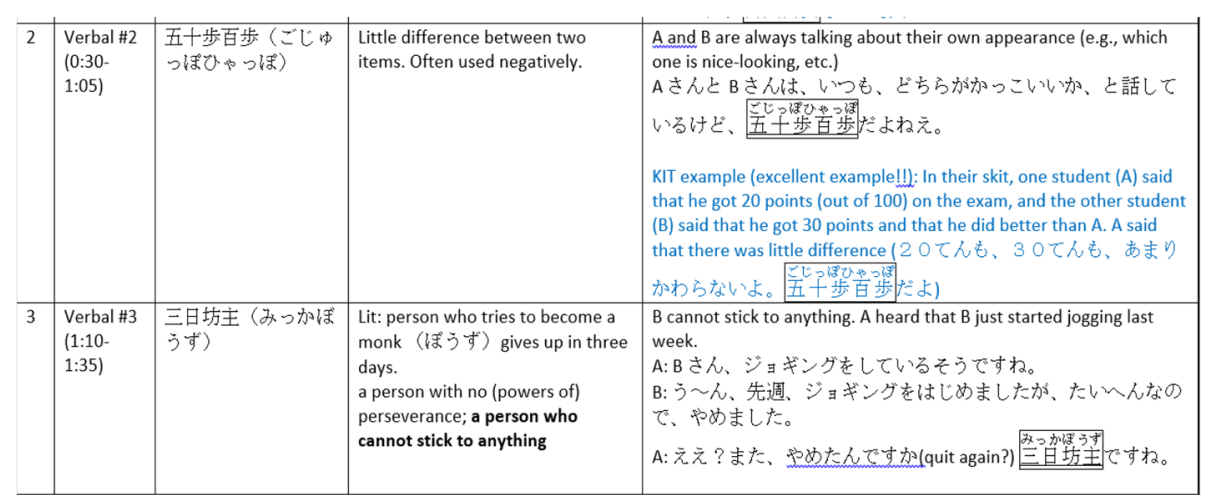

Fig. 3 Screenshot of Part of the Expression list

had enough exposure to native speech. Learners in the pilot study often became lost and frustrated while watching NSJ videos. Thus, the researchers prepared a list of the expressions used in the NSJ videos with the meaning of each in English. The participants in the present study referred to the list when working on in-class follow-up sessions and the reflection log described below.

\section{In-class follow up sessions}

Previous studies (e.g., Bardovi-Harlig, 2001; Kasper \& Rose, 2002; Taguchi, 2015b) in general support explicit instruction for the acquisition of pragmatics. The present study thus had in-class sessions to follow up on the introduced expressions. A total of four short follow-up sessions took place in class. In the sessions, each of which lasted 15 min, the class first watched a short NSJ skit for each expression and then read over the information in the expression handout. Then the class briefly went over the meaning and the background of the expression. A total of 20 proverbs were introduced, making it hard to review each expression in great detail and also conduct conversation activities for each expression. In order to avoid an unbalanced number of exercises on particular expressions that would affect the participants' language performance in their L2 skit, no conversation practice was conducted in these sessions. When students had questions regarding the meaning and the use of the expression, the instructor answered them.

\section{Reflection log}

The participants completed a reflection log activity in which they listed the expressions that they learned and wrote how each expression could be used (see Additional file 1). The purpose of this activity was to prompt participants to reflect on and reinforce what they had learned. Another aim was for them to be aware of cultural similarities and differences in proverb use between their L1 and Japanese through the NSJ videos. They were also asked to provide their opinions about cultural similarities and differences in proverbs between the two languages and general comments about Japanese proverbs that they noticed through the NSJ videos (see Additional file 1). 


\section{L2 skit presentations}

After these activities, the participants performed a skit in class. They were encouraged to use a variety of expressions, including proverbs. Each student was required to use at least one proverb in their skit. There were four groups, and each group prepared their skit script together. The participants were required to memorize their lines for their skit. The skits were filmed in class, and the skit videos were posted on the Japanese Facebook page by the instructor (see Fig. 4).

The L2 skits were later transcribed by a native Japanese-speaking research assistant. The researchers then verified all transcripts for accuracy.

\section{Self-evaluation questionnaires}

We designed a set of self-assessment questionnaires for students to complete before and after the project. They were based on the AACU (Association of American Colleges \& Universities, n.d.) Intercultural Knowledge and Competence VALUE Rubric (see Additional file 2 for the questionnaire). ${ }^{3}$

AACU referred to Bennett's DMIS (Bennett, 1993) and Deardorff (2006) to develop the criteria for learning outcomes. The rubric includes three major elements: knowledge, skills, and attitudes. Each element consists of two specific components: knowledge (1. cultural self-awareness, 2. cultural worldview frameworks), skills (3. empathy, 4. language communication ${ }^{4}$ ), and attitudes (5. curiosity, 6. openness), each of which (1-6) lists four descriptors (levels 1-4). Among these six components, language communication looks at the understanding of cultural differences and the ability to use language communication. This component is directly related to foreign language skills, and the skill levels range from level 1 (inability "to negotiate a shared understanding") to level 4 (ability to "skillfully negotiate a shared understanding"). The first two levels (levels 1-2) describe the ability to recognize minimal or a few cultural differences that roughly correspond to the descriptions of the ethnocentric stages in Bennett's DMIS, whereas the next two levels (levels 3-4) correspond to those of the ethnorelative stages: the recognition and acceptance of cultural differences (Bennett, 1993). Each level includes a knowledge-related descriptor (e.g., level 1: understanding of cultural

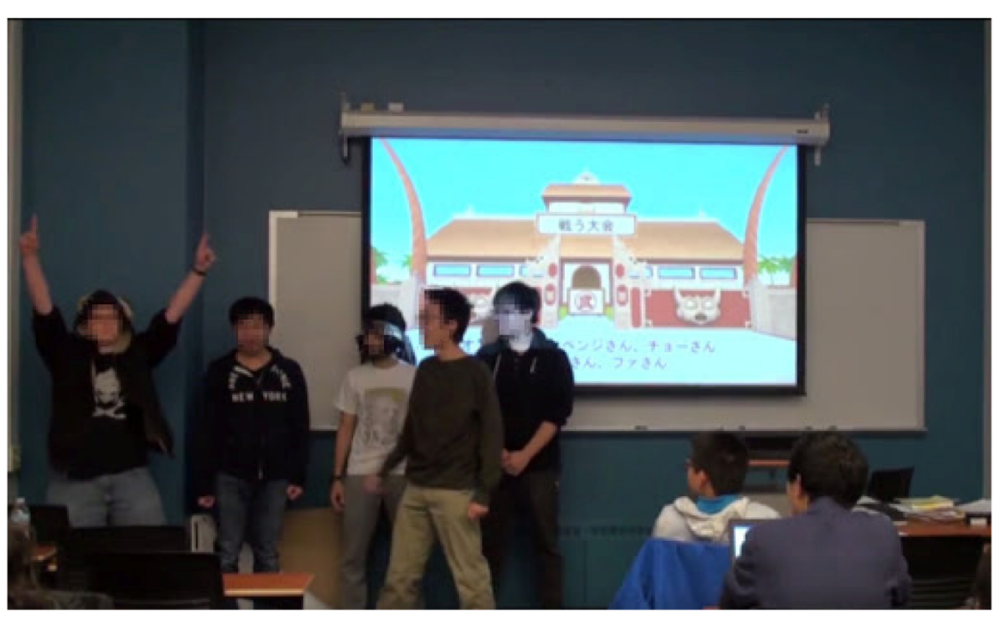

Fig. 4 Screenshot of a L2 Skit 
differences in language communication) and performance skill descriptor (e.g., level 1: is unable to negotiate a shared understanding). Thus, we treated these two descriptions separately and created two sections (Section A for knowledge and Section B for skills).

In the post-project questionnaire, the participants were also asked to answer the following additional items: 1) their sense of accomplishment regarding language communication knowledge and skills, using a Likert scale rating from 1 to 5 with an explanation of why they chose the rating, 2) the most useful activities for improving their verbal communication, and 3) their opinions about their experience learning the expressions taught by the NSJ students through telecollaboration.

\section{Data analysis}

To answer Research Question 1, the two questionnaires were compared using the Wilcoxon Signed Ranks test, a non-parametric statistical hypothesis test to compare two related samples. All statistical analyses for the present study utilized SPSS. The significance level was set at alpha $=.05$.

For the second research question, the L2 skit data were analyzed using the following criteria. We examined how well each expression was used in terms of grammar, pronunciation, and contextual appropriateness using a scale of $0-2$. Grammatical accuracy was examined by looking at the conjugation, tense, and grammatical particles used in the clause as follows: two points if no grammatical errors were observed, one point for minor errors (e.g., "uou-saou shimasu (correct: uou-saou shiteimasu) (S7) [I'm going hither and thither]"), and zero points if the errors affected the understanding of the meaning. The pronunciation of each case was rated as follows: Two points if a native Japanese speaker would clearly understand, one point if the expression sounded unnatural but it was still recognizable (e.g., "isseki-nichuu (correct: nichoo) desune (S17) [That's killing two bird with one stone, isn't it?]"), and zero points if a native Japanese speaker would struggle to understand what was said due to the wrong pronunciation. (e.g., "jigachin (correct: jigajisan) desu ne (S11) [You are blowing your own horn, aren't you?]”). Finally, for contextual appropriateness, we examined whether each expression was used in an appropriate situation. If it was used in a proper situation, two points were given. If it was not used in an appropriate situation, but the meaning of the expression made sense in the context, one point was given. For example, there was a fighting match between two fighters, S9 and S15 in one skit. One fighter (S9), who declared himself the strongest man on the planet, was easily knocked down by S15. When S9 said "aa, shippaishita [oh, I failed]," S15 said "kooboo-nimo-fudeno-ayamari desune [Everyone makes mistakes, don't they?]." Here, it sounds ok if you look at the English meaning. However, this expression is often used to comfort the person, and it is somewhat unnatural to use when a person beats an opponent. Thus, in this case, one point was given. If both the situation and meaning were wrong, zero points were given.

All ratings were conducted by the two researchers in separate rooms, and the interrater reliability was acceptable (alpha $=.86)$. Any disagreements in rating were negotiated until consensus was reached.

As mentioned earlier, the use of expressions in a contextually appropriate situation is an important skill for the development of ICC. Thus, we also qualitatively examined pragmatic (i.e., contextual) appropriateness, focusing on inappropriate uses and the factors that may have affected that use. 


\section{Results and discussion}

The questionnaire and skit data were divided into the different L1 groups (i.e., English, Chinese, and Arabic speakers) and examined for differences in the results of the self-evaluation for the questionnaires and ratings based on L1. No significant statistical differences in the results and the ratings were found; thus, the data for all L1's were combined for the analysis. The following sections will answer the research questions.

RQ1: did L2 learners of Japanese improve their perceptions of their own intercultural communicative competence for verbal communication knowledge and skills after participating in this project?

The following table shows the results of the descriptive statistics. The question that was asked of the participants was "Which of the following statements best describes your knowledge (A) and skills (B) for intercultural communication in verbal communication (A-1 and B-1)? " The participants' scores in all sections increased from the preto the post-project questionnaires. The average student rated their verbal communication knowledge and skills between 2.42 (A-1) and 2.11 (B-1) on the pre-project, whereas he/she provided ratings between 3.05 (A-1) and 3.00 (B-1) on the post-project, respectively (Table 1$)$.

The Wilcoxon Signed Ranks tests showed a significant difference between the preand the post-project questionnaire items: A-1 $(\mathrm{z}=-2.68, P<.01)$ and $\mathrm{B}-1(\mathrm{z}=-3.53$, $P<.01)$ as shown in Table 2.

The results show that the learners gained a sense of accomplishment from learning the target elements of verbal communication through the project. The average student rated their knowledge and skills around 3 (A-1: 3.05; B-1: 3.00) at the end of the project (Table 1), which indicates level 3 of the AACU rubric and corresponds to the ethnorelative stages in Bennett's model (Bennett, 1993). These results were based on the participants' self-evaluation, and thus the results should be treated cautiously. However, when closely examining their reflection logs, we found that many of their opinions exhibited descriptions of the ethnorelative stages and corroborated the statistical results. For instance, S8 (L1: English) pointed out "the Japanese seem to use symbolic idiomatic expressions more often than we do as Americans". Additionally, quite a few of the expressions introduced seemed to have slightly negative connotations i.e. "Mikka-bouzu [A person who cannot stick to anything]" or "Tariki-hongan [Rely on other people]". Likewise, S9 (L1: English) mentioned "(it) also seems like some Japanese phrases are less literal or are abbreviated/not full phrases." In their statements, students express the attitude that "cultural difference is neither good nor bad, it is just different" (Bennett, 1993, p. 46), and we see that they began "to recognize differences in communication style (p. 48) and accept them. These examples show that their respect for behavioral difference corresponds to IV: Acceptance, the first ethnorelative sub-stage. As

Table 1 Descriptive statistics of verbal communication knowledge and skill

\begin{tabular}{llllll}
\hline & \multicolumn{2}{l}{ Pre-project } & & & Post-project \\
\cline { 2 - 3 } & M & SD & & M & SD \\
\hline A-1 Knowledge & 2.42 & .607 & & 3.05 & .705 \\
B-1 Skill & 2.11 & .315 & 3.00 & .577 \\
\hline
\end{tabular}


Table 2 Wilcoxon Signed Ranks tests between the pre- and the post-project questionnaires

\begin{tabular}{lllll}
\hline & Type of ranks & $N$ & Z & P-value (2-tail) \\
\hline A-1 Knowledge & Negative Ranks & 2 & -2.68 & .007 \\
& Positive Ranks & 12 & & \\
Ties & 5 & & \\
Total & 19 & -3.53 & .000 \\
B-1 Skill & Negative Ranks & 1 & & \\
& Positive Ranks & 16 & \\
& Ties & 2 & & \\
& Total & 19 & \\
\hline
\end{tabular}

mentioned earlier, many Japanese proverbs were originally borrowed from China. Chinese students seemed to recognize the importance of understanding the background of proverbs to use them in appropriate context in each culture. For instance, S16 (L1: Chinese) pointed out, "The Chinese and Japanese Culture are both high-context culture, you cannot really understand the meaning of an expression until you know the story behind it." This statement shows his ability to accept "the different worldview assumptions that underlie cultural variation in behavior" (Bennett, 1993, p. 49) and shows his respect for value differences, which also corresponds to IV: Acceptance. The participants did not have much exposure to proverbs in class before this project, but the experience fostered interest in these expressions, and the learners enjoyed learning about cultural differences.

When asked to provide opinions on their experience in learning expressions in the post-project questionnaire, the learners tended to provide detailed and positive comments, such as, "The additional expressions were very useful! since they were chosen by people who actually use them. I was actually very surprised that now while watching anime, I notice many of the phrases we learned. At least 5-10 of them have shown up while watching shows" (S9, L1: English). For native Chinese speakers, many of the proverbs were already familiar in their L1. However, they did not know that Japanese people used these expressions: "The project is really helpful for improving my verbal communication skills" (S2, L1: Chinese). S2 mentioned he felt that he learned many expressions in the Japanese settings.

When the participants were asked to rate their sense of accomplishment on a 5-point Likert scale in the post-project questionnaire (Additional file 2), the majority felt that they improved their verbal communication knowledge and skills through this project $(\mathrm{M}=3.89$; $\mathrm{SD}=.782)$. Their high rating of their sense of accomplishment might positively influence their acquisition of the target language. Thus, it would be worth conducting a questionnaire and collecting their language data at multiple points during the project phase to examine the relationship between their sense of accomplishment and their acquisition of the target language.

In summary, we found that the learners gained a sense of accomplishment by learning proverbs through this project. Researchers (Belz, 2002; O’Dowd, 2005) pointed out a curriculum difference as one of the issues that hinder the integration of telecollaboration into foreign language education. Similarly, our verbal communication project lasted only 4 weeks due to the curriculum restriction. Nonetheless, a noticeable improvement of the L2 learners' ICC perceptions was observed. As we reviewed earlier, 
previous studies on other L2 (Blattner \& Fiori, 2009; Gonzáles, 2013; Lomicka \& Lord, 2016; Mitchell, 2012; Stevenson \& Liu, 2010) reported various benefits of the use of SNS for telecollaboration. Our study showed that the learners of Japanese also received benefits in terms of the improvement of their ICC perceptions, and that it is worth integrating a telecollaboration project into the language curriculum. We designed the project activities (questionnaires and reflection log) with reference to Bennetts' DMIS and the AACU rubric and observed substantial changes in the L2 learners' perceptions. We believe that it would be beneficial to design project activities and materials with reference to ICC models or ICC rubrics that would lead L2 learners to be aware of the improvement of their ICC knowledge and skills.

RQ2: did they use proverbs with grammatical accuracy, correct pronunciation, and in the appropriate context?

\section{General observation of the use of proverbs in L2 skits}

Of the 20 proverbs ${ }^{5}$ introduced by the NSJ students, 15 verbal expressions were actually used in their L2 skits, as shown in Table 3.

Seven proverbs were used multiple times by the same groups or by different groups, and a total of 30 cases were observed. The number of proverbs used per student was 1.58.

Table 3 All proverbs introduced by NSJ students

\begin{tabular}{ll}
\hline Proverbs [meaning] & No. of cases used in L2 skits \\
\hline Koubou-nimo-fude-no-ayamari [Everyone makes mistakes] & 2 \\
Nikai-kara-megusuri [Do something useless] & 0 \\
Junpuu-manpan [Smooth sailing] & 2 \\
Uou-saou [Go hither and thither] & 1 \\
Juunin-toiro [There are as many opinions as there are people] & 4 \\
Jigajisan [Blow your own horn] & 1 \\
Gojuppo-hyappo [Six of one and half a dozen of the other] & 1 \\
Mikka-bouzu [A person who cannot stick to anything] & 1 \\
Hyakubun-wa-ikken-ni-shikazu [Seeing is believing] & 0 \\
Seisei-doudou [Fair and square] & 1 \\
Kyoumi-shinshin [Very interested in] & 1 \\
Neko-no-te-mo-karitai [We are busy. We'll take any help we can get] & 0 \\
Kiki-ippatsu [Close call] & 6 \\
Isshou-kenmei [Doing one's best] & 3 \\
Ishin-denshin [Heart-to-heart communication] & 0 \\
Isseki-nichou [That's killing two birds with one stone] & 1 \\
Iki-tougou [Hit it off] & 1 \\
Koukai-sakini-tatazu [lt is no use crying over spilt milk] & 2 \\
Zen-wa-isoge [Strike while the iron is hot] & 1 \\
Tariki-hongan [Rely on other people] & 3 \\
Total & 2 \\
\hline
\end{tabular}


Table 4 The ratings of the Language Use

\begin{tabular}{ll}
\hline Category & Mean score out of 2 (rating) \\
\hline Grammar & $M=1.87(93.5 \%)$ \\
Pronunciation & $M=1.63(81.5 \%)$ \\
Contextual appropriateness & $M=1.67(83.5 \%)$ \\
\hline
\end{tabular}

\section{Examination of the use of proverbs}

The following table shows the results of the ratings for language use conducted by the researchers (Table 4).

The mean score for grammar $(\mathrm{M}=1.87$ out of $2.0 ; 93.5 \%)$ was slightly higher than that of pronunciation $(M=1.63)$ and contextual appropriateness $(M=1.67)$. Many proverbs are structurally easy to employ. This might be the reason why the rating for grammar was higher than those of the other categories. On the other hand, all proverbs used in the L2 skits contained words that the participants had not yet learned and thus were not accustomed to pronouncing, though they practiced each pronunciation at least couple of times in the follow-up sessions. This might account for the lower scores for pronunciation. In fact, 12 students out of 19 failed to pronounce the proverbs correctly at least once in their skits. For contextual appropriateness, while some proverbs, such as "kiki-ippatsu [close call]," are relatively easy to understand and use in an appropriate situation, others, such as "koubou-nimo-fude-no-ayamari [Everyone makes mistakes]," require background knowledge of the proverb. In other words, the NSJ videos, the vocabulary list, and the in-class follow-up sessions might not provide sufficient information for the use of some proverbs.

Overall, while the participants accurately used proverbs in terms of grammar, the pragmatic appropriateness was relatively low. There are many factors that caused the participants to improperly use the expressions. The rest of this section discusses NSJ influences, followed by other factors.

When examining the NSJ videos for contextual appropriateness and comparing them with the L2 skits, we observed both positive and negative influences for the use of proverbs. Among the 30 cases of the use of proverbs in the L2 skits (Table 3), we found that 13 cases ( 9 proverbs) were used in similar situations to those that NSJ students used in their NSJ videos. Table 5 summarizes the cases.

There were five proverbs ( 8 cases) where we saw positive influences. These expressions (1-5 in Table 5) are frequently used in conversation and do not have pragmatic constraints. Thus, they appeared to be easy for the NSJ students to introduce, and the NSJ students showed how to use them in appropriate situations.

Table 5 Proverbs used in the similar situation to the NSJ videos

\begin{tabular}{ll}
\hline Positive or negative influence (no of cases) & Proverb (no of cases) \\
\hline Positive influence (8) & 1. Gojuppo-hyappo [Six of one and half a dozen of the other] (1) \\
& 2. Mikka-bouzu [A person who cannot stick to anything] (1) \\
& 3. Kiki-ippatsu [Close call] (3) \\
& 4. Isshou-kenmei [Doing one's best] (2) \\
& 5. Iki-tougou [Hit it off] (1) \\
& 6. Koubou-nimo-fude-no-ayamari [Everyone makes mistakes] (1) \\
Negative influence (5) & 8. Junpu-manpan [Smooth sailing] (2) \\
& 9. Kyoumi-shinshin [Very interested in] (1) \\
\hline
\end{tabular}


It also seemed easy for the participants to understand when to use these expressions. In fact, several participants mentioned in their reflection logs that some of the proverbs, such as "kiki-ippatsu [close call]" (S7, L1: English) and "seisei-doudou [fair and square]" (S15, L1: Chinese), were easy to understand and use. For example, when introducing how to use "kiki-ippatsu [close call]," one NSJ group showed one student (B) being almost hit by a car and had the following conversation.

A: ee ... koutsuujiko ni atta tte kiitakedo, daijoubu? [Um ... I heard that you got a car accident. Were you ok?]

\section{B: kiki-ippatsu de tasukatta yo. arigatoo. [(That was) kiki ippatsu. Thank you for asking.]}

Now, looking at L2 data, one L2 group seemed to almost copy the situation when creating their skit. One student (S6: Chinese), who was on her way to her group meeting, was almost hit by a car. When she talked about the incident to her group members (S16 and S19), they asked if she was ok as follows:

S16 and S19: daijoubu desu ka. [Are you ok?]

S6: hai, daijoubu desu yo. demo, kiki-ippatsu deshita. [Yes, I'm fine, but (that was) close]

In this way, when examining other examples $(1,2,4$, and 5 in Table 5), although the situations that L2 students used were not always exactly the same as those that NSJ students provided, L2 learners seemed to refer to those NSJ situations and used them appropriately.

While we saw positive influences on the use of expressions discussed above, we also found negative influences. These negative influences were observed for more situationally restricted expressions (6-9 in Table 5). The NSJ students introduced these expressions in awkward settings. It seemed that the participants referred to these situations for their skits, and there were in fact many examples where students almost 'copied' the situations that NSJ students used. For instance, in case of "koubou-nimo-fude-no-ayamari [Everyone makes mistakes]," as mentioned earlier, it is unnatural to use this expression in a situation like a tournament. However, one NSJ group introduced it through a skit where a rock-paper-scissors tournament took place. In one L2 skit, as we saw previously, the students used the expression in a similar situation (i.e., fighting match) based on the NSJ group's skit. Although the instructor explained how to use these expressions in appropriate situations in the follow-up sessions, the participants still seemed to receive negative influences. The data analysis revealed that NSJ students did not necessarily understand the use of their L1 (Japanese) proverbs, and that the participants referred to NSJ videos at least to some degree for their language production. L2 learners preferred to learn from their native speakers' peers as we saw in the pilot study, and the participants referred to their skits as a model; however, their peers did not always use the language in accordance with traditionally prescribed standards. Future projects should include a more hands-on approach in the instructions to the scripting of the videos by the NSJ students, thus ensuring that they fully understand the use of the expressions selected before they record their skits.

While the NSJ videos were the major factor that influenced the L2 learners' performances, they were not the only factor that led to the participants' pragmatic errors. There were instances where participants made errors in contextual appropriateness for the 
expressions that had been correctly introduced by NSJ students. One factor was the difficulty level of some of the introduced expressions used in L2 skits. Some proverbs (e.g., "junpuu-manpan [Smooth sailing]" require background knowledge of the proverb. When introducing expressions that are so pragmatically challenging to use, we would first need to spend more time to provide detailed background information about the expressions.

Another factor was the potential for negative influence from the participants' L1. Cohen (2011) claimed that a negative transfer of pragmatic behaviors from learners' L1 is a factor that could lead to pragmatically inappropriate language production. In fact, the reflection logs indicated that the learners tended to match the new L2 expressions with similar ones found in their L1. In their skit, they tried to use the expressions in situations typical for their L1. For instance, in one group's skit, students discussed what activity they would do next. When S7 (L1: English) suggested they watch anime, S5 (L1: Chinese) mentioned that he didn't like anime. Then S7 used juunin-toiro [There are as many opinions as there are people] as follows:

\section{S7: aa...watashino ... etto ... video o miyou ka. kore wa watashi no ichiban sukina anime desu. [Um ... Shall we watch my ... video? This (pointed at one video) is my favorite anime]}

S5: aa ... anime ga chotto suki janai ... [Well ... I don't care for anime..].

S7: nn.. soune. juunin-toiro kanaa.. nn ... geemu wa doo? [OK. I see. Juunin-toiro, isn't it? How about videogames?]

For S7 part, a native speaker would say, "Anime wa suki kirai ga arukara ne [For anime, people either like it or dislike it]". Juunin-toiro is often used when people receive different opinions and try to conclude the discussion while respecting all opinions. We assume that S7 probably simply looked at the English translation (There are as many opinions as there are people) and used the expression in the above context.

This section has highlighted factors that may have resulted in pragmatic inappropriateness for the use of the proverbs. Participants indicated that some of the proverbs were challenging to use appropriately. Many participants, including native Chinese speakers, asked for the meaning and the cultural background of these expressions during the in-class review sessions. When learners are still uncertain about the appropriate use during the acquisition process of the target expressions, they might be more likely to imitate the situation used by L1 speakers. However, there were also some cases (e.g., jigajisan [Blow your own horn] and isseki-nichou [That's killing two birds with one stone]) where they created their own situations and correctly used the expressions. When L2 learners feel more comfortable with the expressions, they might try a wider variety of situations. Further studies need to examine in what circumstances learners imitate L1 speakers' situations to support this claim.

The results of our study are interesting when compared to the findings of Kakegawa's research on L2 pre-intermediate learners' use of SFPs through telecollaboration that we reviewed earlier (Kakegawa, 2009). Kakegawa reported L2 learners developed their use of sentence final particles in terms of the frequency of the use and the improvement of their accuracy. At the same time, her findings also revealed that her participants did not always use the target particles appropriately, and she pointed out that their errors 
on the target particles in terms of contextual appropriateness remained throughout the data collection period. In our study, although we observed inappropriate use of proverbs in the learners' language production due to the factors discussed above, they learned the new expressions through a series of telecollaboration activities (i.e., NSJ videos, reflection logs, in-class follow-up sessions, and L2 skit preparation) and used the expressions appropriately in the majority of the situations (83.5\%). Like Kakegawa's study (Kakegawa, 2009), we thus claim that telecollaboration helped the students in our study improve their ability to use expressions in contextually appropriate situations.

\section{Pedagogical implications}

This paper have examined benefits of telecollaboration, focusing on L2 learners' ICC perceptions and their language use. Based on the findings of the present study, we identified three areas where there are pedagogical implications: 1 ) teaching of proverbs, 2) pronunciation and 3) integration of telecollaboration into the novice-level language curriculum.

The post-project questionnaire revealed that the majority of the participants thought that the proverb expression list, followed by the in-class follow-up sessions, was the most beneficial for improving their understanding and use of proverbs in verbal communication (Additional file 2). Consistent with previous research (e.g., O'Dowd, 2007; O’Dowd \& Ritter, 2006), this finding suggests explicit instruction to be an effective means for teaching proverbs. Our results also show that explicit instruction is needed to reinforce students' knowledge of expressions in relation to different contexts. Previous research demonstrated the positive effects of L1 use to convey and explain the meaning of target expressions (Cook, 2001). While L1 instruction is not always feasible in multicultural academic settings, the use of a language in which the learners presumably have sufficient competence to at least understand the explanations (e.g., in the present case, English) should be considered. A typical novice learner does not have the vocabulary for understanding the background information of proverbs in the target language. Some proverbs are not pragmatically easy to understand due to subtle differences between languages (Neale, 2015); nonetheless, in the present study several students mentioned in their reflection logs that they have the same or similar expressions in their L1 and did not analyze the expressions for subtle differences. The data indicates that learners did not pay close attention to those cross-cultural differences due to the similarity in meaning and thus assumed that the expressions would be used in the same way in the L2. One suggestion to help stimulate learners' interest in those subtle differences would be to draw more attention via written explanations to the differences in English and have in-class discussion in English if necessary. Supplementary materials written in English would be beneficial and may even be necessary to effectively acquire pragmatically difficult expressions.

Turning now to the second implication, although none of the participants indicated a desire for pronunciation exercises or materials in their post-project questionnaire, their accuracy scores on pronunciation tended to be lower than those of grammar. Previous research (e.g., Saito, 2011) suggests that explicit instruction facilitate the improvement of pronunciation. Although the participants practiced the pronunciation of each expression during the in-class follow-up sessions, more salient tasks are necessary. For instance, students can work on pair-work activities where they check their partner's 
intonation and pronunciation in class. Then they can do audio tasks for homework that require them listen to L1 pronunciation, work on intonation/pronunciation check tasks, and record their pronunciation.

Concerning the integration of telecollaboration in the foreign language classroom, the participants who were novice learners felt a high sense of accomplishment in learning proverbs through telecollaboration. Although it might have been challenging for novice learners to collaborate with native speakers due to their limited proficiency in the target language, the participants were able to understand the NSJ videos and completed all project assignments with explicit instruction. Novice-level students can learn many expressions during and even after telecollaboration. Learners can still review the same expressions and learn new relevant expressions in class after telecollaboration ends. The present proverbs project ended in the fall, but the class often used the expressions during in-class activities and learned relevant proverbs in the winter. The learners used many expressions that they liked, such as "kiki-ippatsu [close call]" in class conversations and short skit activities in the winter. Although it is often challenging to conduct long-term telecollaboration due to different curricula between schools, learners can continue to review the expressions that they have learned and learn relevant expressions after telecollaboration, which would reinforce the acquisition of target expressions.

\section{Conclusion}

This study examined the effects of telecollaboration on L2 learners' perceptions of their ICC knowledge and skills in relation to proverbs and analyzed the use of these expressions in their language production. The use of explicit instruction facilitated the activities and helped the students gain a sense of accomplishment in learning the target element of verbal communication. With regard to their language use, the participants accurately used the expressions in terms of grammar, but they did not always execute them in an appropriate context. Based on the results of this study, future courses will need to incorporate in-class extensive and explicit instruction in English to improve learners' ability to use proverbs in pragmatically appropriate ways.

As for the limitations of the present study, first, due to the curriculum restriction, the project lasted only 4 weeks. In order to observe students' acquisition process, a longer experiment will be necessary. Moreover, since we used L2 skits as the language data, the number of proverbs used per student was small (1.58), and thus we treated the L2 language data as a whole group data set rather than as individual data. In the present study, the participants listed 10 proverbs that they had learned through NSJ videos. In further research, we can assign an additional activity where each student produces one skit for each proverb that he/she lists in their reflection log (i.e., If he/ she lists 10 proverbs, he/she produces 10 short skits) to examine individual learner's data and investigate their acquisition process. Furthermore, this study focused on a limited set of verbal expressions and did not examine learners' overall verbal communication knowledge and skills. Including a wider range of expressions and contexts would provide more insight into students' understanding of verbal expressions in relation to given contexts.

Although it is challenging to conduct long-term telecollaboration projects due to different schedules and curricula between schools, there are many potential positive outcomes, such as facilitating learners' awareness of similarities and differences between 
their own culture and the target culture as well as their awareness of the use of target expressions. This type of project assists learners in their development of their intercultural communicative competence.

\section{Endnotes}

${ }^{1}$ Although the data collection for this study occurred over a four-week period, the collaboration between the two schools actually lasted for 4 months. Differences in the curriculums and the academic calendars of the two schools meant that it was not possible to conduct data collection over a longer period of time.

${ }^{2}$ In addition to proverbs, NSJ students also introduced gestures (a total number of 9 gestures) in their videos.

${ }^{3} \mathrm{AACU}$ developed 16 rubrics for learning outcomes to assess students' skills that they are expected to acquire through college education (https://www.aacu.org/value-rubrics). Many institutions, including one of the researchers' institutions, have used these rubrics as valid and reliable rubrics (Clark \& Eynon, 2012; Finley, 2011). The intercultural knowledge and competence VALUE Rubric is one of the rubrics.

${ }^{4}$ The rubric describes communication skills as "verbal and nonverbal communication" skills. However, since the present study dealt with verbal communication only, we described the skills as "language communication skills" in text.

${ }^{5}$ All proverbs are included in proverb dictionaries (e.g., http://kotowaza-allguide.com/).

\section{Additional files}

Additional file 1: Reflection log on verbal and non-verbal communication. (DOCX 263 kb)

Additional file 2: Pre- and post-project questionnaires. (DOCX $272 \mathrm{~kb}$ )

\section{Abbreviations}

AACU: Association of American Colleges and Universities; DMIS: The Developmental Model of Intercultural Sensitivity; ICC: Intercultural communicative competence; L1: The first language; L2: The second language; MLA: The Modern Language Associations

\section{Acknowledgements sharing their expertise. \\ Funding \\ Not applicable: No funding was received. \\ Availability of data and materials \\ Data will be available upon request.}

We are indebted to the students at our respective universities who kindly consented to the use of their data, without which this study would not have been possible. We would also like to send our gratitude to Professor Brent Wright and Professor Casey Bean at Kanazawa Institute of Technology for taking their time to proofread our manuscript and

Authors' contributions

The Principal Investigator and co-investigator developed and conducted the project. PI designed the study, employed statistical analyses, and wrote the manuscript draft. Cl helped revise the manuscript. Both authors read and approved the final manuscript.

Competing interests

The authors declare that they have no competing interests.

\section{Publisher's Note}

Springer Nature remains neutral with regard to jurisdictional claims in published maps and institutional affiliations.

\section{Author details}

${ }^{1}$ Rose-Hulman Institute of Technology, 5500 Wabash Ave., Terre Haute, IN 47803, USA. ${ }^{2}$ Kanazawa Institute of

Technology, 7-1 Ogigaoka, Nonoichi, Ishikawa 921-8501, Japan. 
Received: 18 March 2018 Accepted: 14 March 2019

Published online: 18 April 2019

\section{References}

Association of American Colleges \& Universities (n.d.). Intercultural knowledge and competence VALUE rubric. https://www. aacu.org/sites/default/files/files/VALUE/InterculturalKnowledge.pdf. Accessed 20 Dec 2018.

Banno, E., Ohno, Y., Sakane, Y., Shinagawa, C., \& Takashiki, K. (2011). Genki: An integrated course in elementary Japanese Vol. 2, 5th ed.). Tokyo: Japan Times.

Bardovi-Harlig, K. (2001). Empirical evidence of the need for instruction in pragmatics. In K. Rose \& G. Kasper (Eds.), Pragmatics and language teaching (pp. 13-22). Cambridge: Cambridge University Press.

Belz, J., \& Vyatkina, N. (2005). Learner corpus analysis and the development of L2 pragmatic competence in networked intercultural language study: The case of German modal particles. Canadian Modern Language Review, 62, 17-48. https://doi. org/10.3138/cmlr.62.1.17.

Belz, J. A. (2002). Social dimensions of telecollaborative foreign language study. Language Learning \& Technology, 6(1), 60-81 http://dx.doi.org/10125/25143. http://www.Iltjournal.org/item/2373. Accessed 20 Dec 2018.

Belz, J. A. (2003). Linguistic perspectives on the development of intercultural competence in telecollaboration. Language Learning \& Technology, 7(2), 68-117 http://dx.doi.org/10125/25201. http://www.lltjournal.org/item/2431. Accessed 20 Dec 2018.

Belz, J. A., \& Kinginger, C. (2003). Discourse options and the development of pragmatic competence by classroom learners of German: The case of address forms. Lanquage Learning, 53, 591-647. https://doi.org/10.1046/j.1467-9922.2003.00238.x.

Bennett, M. (1993). Towards ethnorelativism: A developmental model of intercultural sensitivity. In R. M. Paige (Ed.), Education for the intercultural experience. Yarmouth: Intercultural Press, Inc.

Blattner, G., \& Fiori, M. (2009). Facebook in the language classroom: Promises and possibilities. International Journal of Instructional Technology and Distance Learning, 6, 17-28. http://www.itdl.org/journal/jan_09/article02.htm. Accessed 20 Dec 2018.

Byram, M. (1997). Teaching and assessing intercultural communicative competence. Clevedon: Multilingual Matters Ltd.

Clark, J. E., \& Eynon, B. (2012). Measuring student progress with e-portfolios. Peer Review, 13(4), 6-8 https://www.aacu.org/ sites/default/files/files/peerreview/PRfa1 1 wi12.pdf. Accessed 20 Dec 2018.

Cohen, A. D. (2011). Learner strategies for performing intercultural pragmatics. Minnesota and Wisconsin Teachers of English to Speakers of Other Languages. Retrieved from the University of Minnesota Digital Conservancy. http://hdl.handle.net/ 11299/162595. Accessed 20 Dec 2018.

Cook, V. (2001). Using the first language in the classroom. Canadian Modern Language Review, 57, 402-423. https://doi.org/10. $3138 / \mathrm{cm} / \mathrm{r} .57 .3 .402$.

Cunningham, J. (2016). Request modification in synchronous computer-mediated communication: The role of focused instruction. Modern Language Journal, 100, 484-507. https://doi.org/10.1111/modl.12332.

Dabaghi, A., Pishbin, E., \& Niknasab, L. (2010). Proverbs from the viewpoint of translation. Journal of Language Teaching \& Research, 1(6). https://doi.org/10.4304/jttr.1.6.807-81.

Deardorff, D. K. (2006). Identification and assessment of intercultural competence as a student outcome of internationalization. Journal of Studies in International Education, 10, 241-266. https://doi.org/10.1177/1028315306287002.

Ellis, N. C. (2012). Formulaic language and second language acquisition: Zipf and the phrasal teddy bear. Annual Review of Applied Linguistics, 32, 17-44. https://doi.org/10.1017/S0267190512000025.

Finley, A. P. (2011). How reliable are the VALUE rubrics? Peer Review, 13(4), 31-34 https://www.aacu.org/sites/default/files/files/ peerreview/PRfa1 1wi12.pdf. Accessed 20 Dec 2018.

Fischer, J. L., \& Yoshida, T. (1968). The nature of speech according to Japanese proverbs. Journal of American Folklore, 81, 3443. https://doi.org/10.2307/537436.

Garrett-Rucks, P. (2016). Intercultural competence in instructed language learning. Charlotte: Information Age Publishing Inc.

Gonzáles, A. (2013). Development of politeness strategies in participatory online environments. In N. Taguchi \& J. M. Sykes (Eds.), Technology in interlanguage pragmatics research and teaching (pp. 101-120). Philadelphia: John Benjamins.

Irujo, S. (1986). Don't put your leg in your mouth: Transfer in the acquisition of idioms in a second language. TESOL Quarterly, 20, 287-304. https://doi.org/10.2307/3586545.

Jeon, E. H., \& Kaya, T. (2006). Effects of L2 instruction on interlanguage pragmatic development. In J. M. Norris \& L. Ortega (Eds.), Synthesizing research on language learning and teaching (pp. 165-211). Philadelphia: John Benjamins.

Kakegawa, T. (2009). Development of the use of Japanese sentence-final particles through email correspondence. In N. Taguchi (Ed.), Pragmatic competence (pp. 301-325). Berlin: Mouton de Gruyter.

Kasper, G., \& Rose, K. R. (2002). Pragmatic development in a second language. Oxford: Blackwell.

Lewis, T., \& O'Dowd, R. (Eds.). (2016). Online intercultural exchange: Policy, pedagogy, practice. New York: Routledge.

Lomicka, L., \& Lord, G. (2016). Social networking and language learning. In F. Farr \& L. Murray (Eds.), The Routledge handbook of language learning and technology (pp. 255-268). New York: Routledge.

McBride, K. (2009). Social networking sites in foreign language classes: Opportunities for re-creation. In L. Lomicka \& G. Lord (Eds.), The next generation: Social networking and online collaboration in foreign lanquage learning (pp. 35-58). San Marcos: CALICO.

Mieder, W. (2004). Proverbs: A handbook. New York: Peter Lang Publishing, Inc

Mitchell, K. (2012). A social tool: Why and how ESOL students use Facebook. CALICO Journal, 29, 471-493. https://doi.org/10. 11139/cj.29.3.471-493.

Modern Language Association Ad Hoc Committee on Foreign Languages. (2007). Foreign language and higher education: New structures for a changed world. Profession, 2007, 234-245.

Neale, M. (2015). A comparison of English and Japanese proverbs using natural semantic metalanguage. New Voices in Japanese Studies, 7, 85-101. https://doi.org/10.21159/nvjs.07.05.

O'Dowd, R. (2005). Negotiating sociocultural and institutional contexts: the case of Spanish-American telecollaboration. Language and Intercultural Communication, 5(1), 40-55.

O'Dowd, R. (2007). Evaluating the outcomes of online intercultural exchange. ELT Journal, 6, 144-152. https://doi.org/10.1093/ elt/ccm007. 
O'Dowd, R., \& Ritter, M. (2006). Understanding and working with 'failed communication' in telecollaborative exchanges. CALICO Journal, 23, 623-642. https://doi.org/10.1558/cj.v23i3.623-642.

Saito, K. (2011). Examining the role of explicit phonetic instruction in native-like and comprehensible pronunciation development: An instructed SLA approach to L2 phonology. Language Awareness, 20, 45-59. https://doi.org/10.1080/ 09658416.2010 .540326$.

Stevenson, M. P., \& Liu, M. (2010). Learning a language with Web 2.0: Exploring the use of social networking features of foreign language learning websites. CALICO Journal, 27, 233-259. https://doi.org/10.11139/cj.27.2.233-259.

Taguchi, N. (2015a). "Contextually" speaking: a survey of pragmatics learning abroad, in class and online. System, 48, 3-20. https://doi.org/10.1016/j.system.2014.09.001.

Taguchi, N. (2015b). Instructed pragmatics at a glance: Where instructional studies were, are, and should be going. Language Teaching, 48, 1-50. https://doi.org/10.1017/50261444814000263.

Taguchi, N., \& Sykes, J. M. (Eds.). (2013). Technology in interlanguage pragmatics research and teaching. Philadelphia: John Benjamins.

Takamiya, Y., \& Ishihara, N. (2013). Blogging: Cross-cultural interaction for pragmatic development. In N. Taguchi \& J. M. Sykes (Eds.), Technology in interlanguage pragmatics research and teaching (pp. 185-214). Philadelphia: John Benjamins.

Weinert, R. (1995). The role of formulaic language in second language acquisition: A review. Applied Linguistics, 16, 180-205. https://doi.org/10.1093/applin/16.2.180.

Submit your manuscript to a SpringerOpen ${ }^{\odot}$ journal and benefit from:

- Convenient online submission

Rigorous peer review

- Open access: articles freely available online

- High visibility within the field

- Retaining the copyright to your article

Submit your next manuscript at $\boldsymbol{\nabla}$ springeropen.com 